
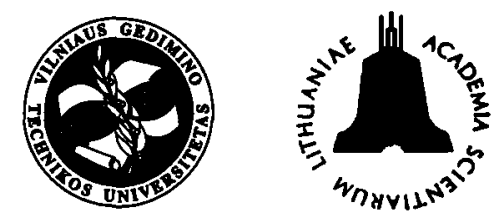

ISSN 1392-3730

JOURNAL OF CIVIL ENGINEERING AND MANAGEMENT

http:/www.vtu.It/english/editions

2003, Vol IX, No 3, 172-177

\title{
EFFECT OF WOVEN FABRIC ON THE SHEAR CAPACITY OF SHORT RC BEAMS
}

\author{
Hau-yan Leung \\ Dept of Building and Construction, City University of Hong Kong, \\ Tat Chee Avenue, Kowloon, Hong Kong SAR, China.E-mail: bchyl@cityu.edu.hk
}

Received 30 Jan 2002; accepted 15 June 2002

\begin{abstract}
Recently, externally bonded fibre-reinforced polymer (FRP) composite plate has been used successfully to enhance the performance of reinforced concrete (RC) members. The non-corrosive property of FRP eliminates the corrosion problem, but the occurrence of premature cracking induced by the rigidity of FRP plates is still questionable. In current pilot study, woven fabric is adopted, in lieu of rigid plates, to provide the strengthening effect. An experimental programme was developed and a series of short RC model beams, including unloaded and preloaded specimens, were prepared and woven fabric straps were attached. Ultimate loading tests were carried out and the results were recorded. All specimens were specially designed to investigate the effect of woven fabric on the shear capacity of RC beams. The results demonstrate that the shear performance of both unpreloaded and preloaded RC members can be enhanced by more than $10 \%$ if woven fabrics are employed.
\end{abstract}

Keywords: concrete, RC beam, reinforcement, steel rebar, FRP strap, shear.

\section{Introduction}

Corrosion, fatigue and degradations in many building structures lead to an unacceptable load carrying performance, a reduced service life and high maintenance costs. Apart from these shortcomings, existing damaged structures, which were originally designed according to old design codes, may not even comply with current design regulations. Change of use and overloading are other factors that may aggravate further the structural behaviour of RC members. In order to recover/upgrade the original performance of the structures, some rehabilitation/strengthening techniques have been developed recently.

Application of external steel plates is one of the options that can provide strengthening effects to RC structures. Neelamegam et al [1] carried out an experimental investigation on RC beams with an external steel plate bonded to the tension face at the bottom of the beams. Based on their results, they suggested that provision of end anchorage was important in promoting the ultimate strength and ductility of plated RC beams. Mohamed Ali et al [2] carried out a similar study, but they bonded the steel plates to two sides of RC beams. They found that by using the side plates both the shear and flexural capacities of $\mathrm{RC}$ beam can be enhanced, but the vicinity of the plate ends was prone to debonding. Despite the enhancement in load capacity, the intrinsic problem of steel corrosion still applies.
However, with the advent of innovative synthetic fibres, the corrosion problem can be eliminated. A lot of investigations have focused on using FRP materials to provide external strengthening effect. In 1997, Varastehpour and Hamelin [3] employed FRP plates to retrofit RC beams. They pointed out that the performance was dependent upon the interfacial properties of the bond. Later, Ross et al [4], Sherwood and Soudki [5] and Ramana et al [6] reported that externally bonded carbon FRP plates were used successfully to enhance the performance of RC members, but the occurrence of premature cracking induced by the rigidity of the FRP plates was problematic. A more in-depth discussion on flexural and shear behaviour of beams strengthened with FRP plates can be found elsewhere [7].

In order to eliminate this drawback, woven fabric appears to be an ideal solution, because it is flexible and conformable to any profiles of concrete section. A pilot experimental programme was thus developed to investigate the possibility of using externally bonded woven fabric straps to provide the strengthening effect. The woven fabric was applied to two sides of small RC beams to give additional shear capacity. The effect of preloading was also taken into consideration.

\section{Experimental details}

Small RC beam specimens $100 \times 100 \times 500 \mathrm{~mm}$, including unloaded and preloaded samples, were prepared 


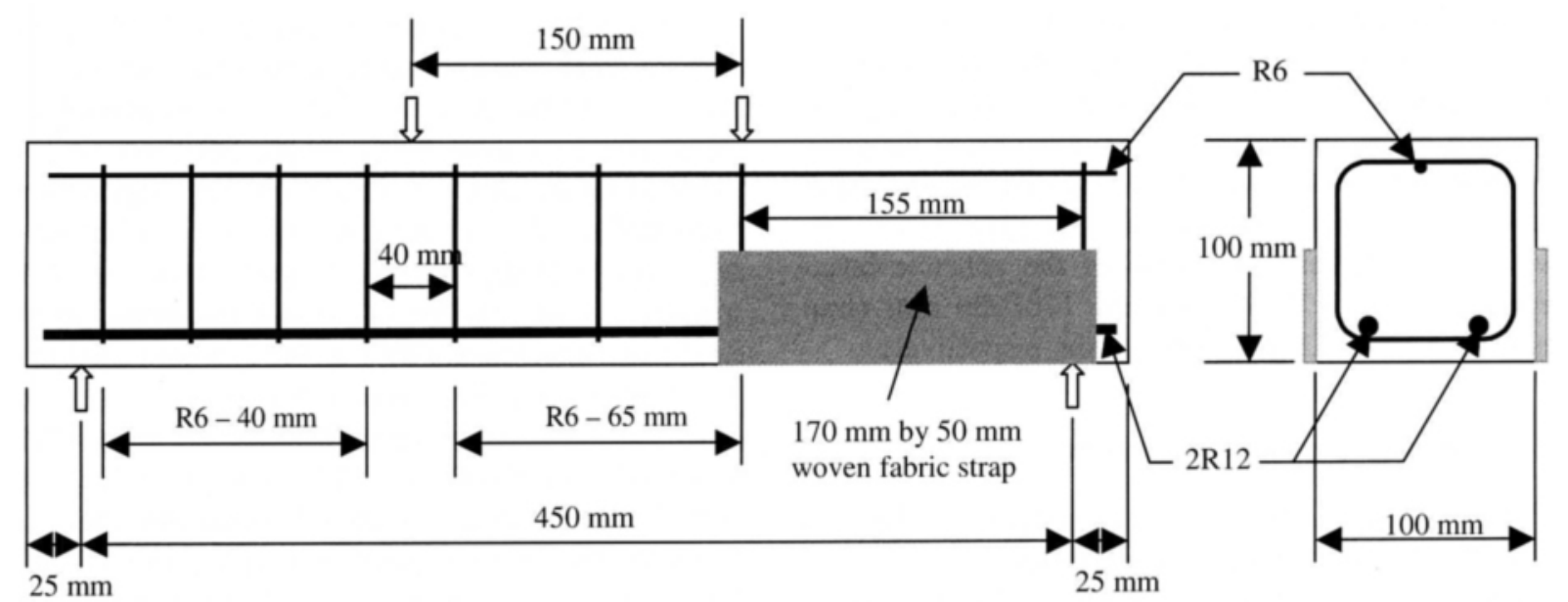

Fig 1. Specimen details

for flexural tests. Steel reinforcement was contained in the concrete matrix, and external woven fabric straps were attached to some of the specimens.

\subsection{Concrete}

In ordinary Portland cement concrete mix, with a $\mathrm{W} / \mathrm{C}$ ratio of 0 , and an $\mathrm{A} / \mathrm{C}$ ratio of 2,63 , was adopted. The maximum aggregate size was $10 \mathrm{~mm}$. The 28-day cylinder strength was found to be $33,5 \mathrm{MPa}$. Details of the concrete mix can be found in Table 1 .

\section{Table 1. Concrete mix}

\begin{tabular}{|c|c|c|c|c|}
\hline $\begin{array}{c}\text { Type of } \\
\text { material }\end{array}$ & Cement & Water & Aggregate & Sand \\
\hline $\begin{array}{c}\text { Quantity } \\
(\mathrm{kg} / \mathrm{m})\end{array}$ & 350 & 210 & 1000 & 820 \\
\hline
\end{tabular}

\subsection{Steel reinforcement}

Since all specimens were designed to fail in shear, a special arrangement of the reinforcing steel was adopted, as shown in Fig 1. Two mild steel (MS) R12 bars were used for flexural reinforcement and one MS R6 as a stimup carrier. For the shear reinforcement, size R6 MS closed loop stirrups with a centre to centre spacing of $40 \mathrm{~mm}$ was adopted at one of the shear spans, whereas no shear stirrups were provided at the other shear span. At the midspan portion, the stirrup spacing was increased to $65 \mathrm{~mm}$.

\subsection{Woven fabric}

The woven fabric consists of glass fibre yarns in longitudinal direction and a mix of glass fibre yarns and aramid yarns in its transverse direction. It is flexible and deformable (Fig 2). It is also observed that, prior to application of epoxy, the colours of the glass fibre yarns and the aramid fibre yarns are silver and yellow respectively (Fig 3 ). In order to use the woven fabric as external shear reinforcement, it was cut to small straps of two

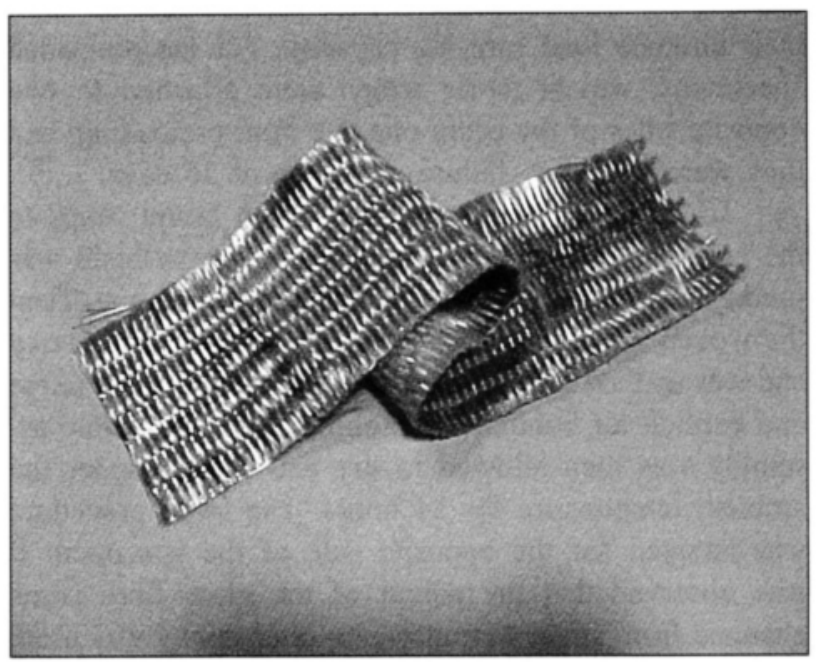

Fig 2. Woven fabric

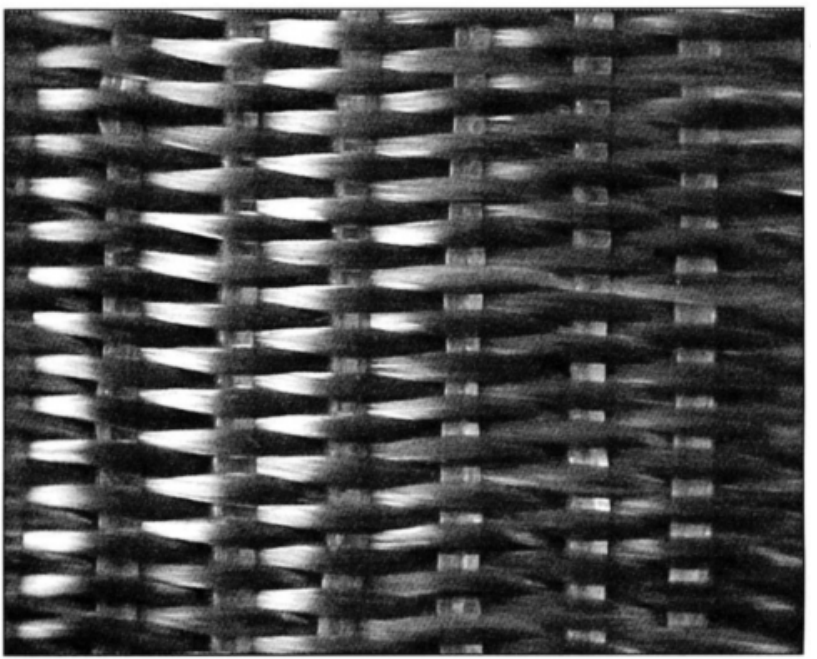

Fig 3. Woven fabric yarns 
different designed dimensions, namely $170 \times 50 \mathrm{~mm}$ and $170 \times 100 \mathrm{~mm}$. The large strap covers the full height of the specimen whereas the smaller strap covers only the lower half height of specimen. The direction of the glass fibre yarns (the stronger direction) is parallel to the longer side of the strap and this direction of glass fibres follows the longitudinal dimension of the concrete beam specimens. Each $170 \times 50 \mathrm{~mm}$ and $170 \times 100 \mathrm{~mm}$ strap contained 11 and 22 glass fibre yarns respectively.

\subsection{Manufacture of test specimens}

The reinforcing steel cages were prepared and placed inside the beam steel moulds, $100 \mathrm{~mm} \times 100 \mathrm{~mm} \times$ $500 \mathrm{~mm}$, prior to casting the specimens. All ingredients of the concrete were thoroughly mixed in a horizontal pan mixer. Full compaction was achieved by means of a vibrating table. All the specimens were demoulded after one day and then water cured for 7 days. At 21 days, some RC beam specimens were externally reinforced with woven fabric straps, and these specimens were tested to failure at an age of 28 days. On the same day, the remaining RC beam specimens were preloaded to $65 \%$ of their ultimate load carrying capacity. For the preloaded specimens, woven fabric straps were attached to two opposite sides of the beam one day after preloading, and they were loaded to failure at an age of 36 days.

To facilitate bonding of the woven fabric straps to the concrete surface, a two-component epoxy resin was used. The bonding area was first coated with epoxy. Then the woven fabric strap was soaked with the same epoxy and was applied gently onto the designated surface. Large and explicit air bubbles were eliminated. The whole assembly was then allowed to dry and harden under the ambient temperature for 24 hours. The same procedure was adopted for the opposite side of the specimen. It was observed that the colour of the glass fibre yarns changed from silver to transparent once epoxy was used. Some properties of the hardened woven fabric are given in Table 2.

Table 3. Testing programme

\begin{tabular}{|c|c|c|c|c|}
\hline $\begin{array}{c}\text { Beam } \\
\text { designation }\end{array}$ & $\begin{array}{c}\text { Woven fabric } \\
\text { strap dimension }\end{array}$ & $\begin{array}{c}\text { Date of applying woven } \\
\text { fabric strap }\end{array}$ & $\begin{array}{l}\text { Age of } 65 \% \\
\text { preloading }\end{array}$ & $\begin{array}{c}\text { Age of } \\
\text { ultimate test }\end{array}$ \\
\hline NS1 & \multirow{4}{*}{ N/A } & \multirow{4}{*}{ N/A } & \multirow{2}{*}{ N/A } & 28 days \\
\hline NS2 & & & & \\
\hline NS3 & & & & \\
\hline NS4 & & & 28 days & 36 days \\
\hline WH1 & \multirow{3}{*}{$170 \mathrm{~mm} \times 50 \mathrm{~mm}$} & \multirow{5}{*}{ 21-22 days } & \multirow{5}{*}{ N/A } & 28 days \\
\hline WH2 & & & & \\
\hline WH3 & & & & \\
\hline WF1 & \multirow{2}{*}{$170 \mathrm{~mm} \times 100 \mathrm{~mm}$} & & & \\
\hline WF2 & & & & \\
\hline WHH1 & \multirow{3}{*}{$170 \mathrm{~mm} \times 50 \mathrm{~mm}$} & \multirow{6}{*}{ 29-30 days } & \multirow{6}{*}{28 days } & 36 days \\
\hline WHH2 & & & & \\
\hline WHH3 & & & & \\
\hline WFH1 & \multirow{3}{*}{$170 \mathrm{~mm} \times 100 \mathrm{~mm}$} & & & \\
\hline WFH2 & & & & \\
\hline WFH3 & & & & \\
\hline
\end{tabular}

A total of 15 concrete specimens, with identical internal steel reinforcement, were manufactured. Four beam specimens (NSl to NS4) served as control specimens with no woven fabric straps. NS1 and NS2 were tested to failure after 28 days while NS3 and NS4 were preloaded to $65 \%$ at the same day and no damage was observed. At 28 days, three half-height strengthened beam specimens (WH1 to WH3) and two full-height strengthened beam specimens (WF1 \& WF2) were tested to failure after bonding the woven fabric straps at 21 days, as shown in Fig 1. At the same day, six specimens (WHH1 to WHH3, and WFH1 to WFH3) were preloaded to $65 \%$ of the loading capacity of the RC beam specimens. One day later, they were bonded with either two $170 \mathrm{~mm} \times$ $50 \mathrm{~mm}$ straps (half-height strengthening) or $170 \mathrm{~mm} \times$ $100 \mathrm{~mm}$ straps (full height strengthening). The detailed testing programme can be found in Table 3. In addition to the beam specimens, six concrete cylinders were cast to determine the compressive strengths of concrete at different testing dates.

Table 2. Properties of hardened woven fabric

\begin{tabular}{|c|c|}
\hline Primary fibre & glass \\
\hline Tensile strength & $450 \mathrm{~N} / \mathrm{mm}^{2}$ \\
\hline Ultimate strain & 0,02 \\
\hline Elastic modulus & $22460 \mathrm{~N} / \mathrm{mm}^{2}$ \\
\hline Strength at $90^{\circ}$ & $41 \mathrm{~N} / \mathrm{mm}^{2}$ \\
\hline Coefficient of thermal expansion & $7,74 \times 10^{-6}{ }^{\circ} \mathrm{C}$ \\
\hline
\end{tabular}

\subsection{Loading setup}

Preloading and ultimate testing were carried out in a $100 \mathrm{kN}$ capacity Lloyd flexural testing machine. All beam specimens were subjected to a 4-point bending arrangement over a span of $450 \mathrm{~mm}$. The length of the constant bending moment region was $150 \mathrm{~mm}$ (Fig 1). Preloading was conducted at an age of 28 days and ultimate tests were performed at 36 days. The failure mechanism was observed and the failure load was recorded. 


\section{Experimental results}

\subsection{Observation and failure pattern}

As can be seen in Fig 4, the four control specimens, including both unloaded and preloaded, show a typical shear failure mode. Concrete cracks initiated at the vicinity of the loading positions. The cracks were inclined and a major diagonal crack was formed during the course of loading. This diagonal crack opened up and the internal steel reinforcement was exposed when failure was reached (Fig 5).

When half-height of a beam specimen (either unloaded or preloaded) was masked with woven fabric straps, a similar phenomenon, as observed from control specimens, was found. An inclined crack propagated, although the lower part of the crack was covered by the straps. At this stage, no debonding or separation of strap was observed. However, when the loading approached the shear capacity of the control specimens, the woven fabric straps started to ear the shearing force, and thus resisted crack opening. When the load was increased

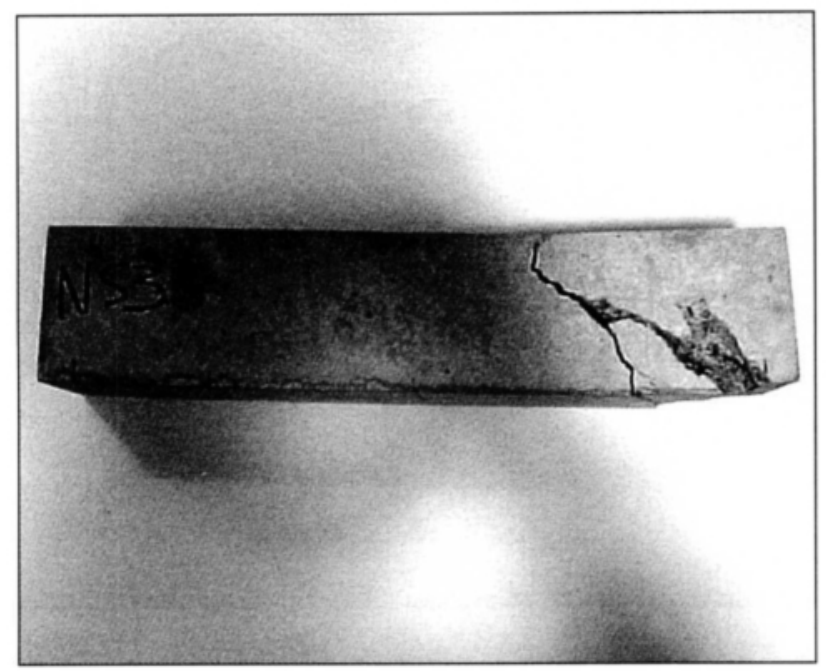

Fig 4. Control specimen at failure

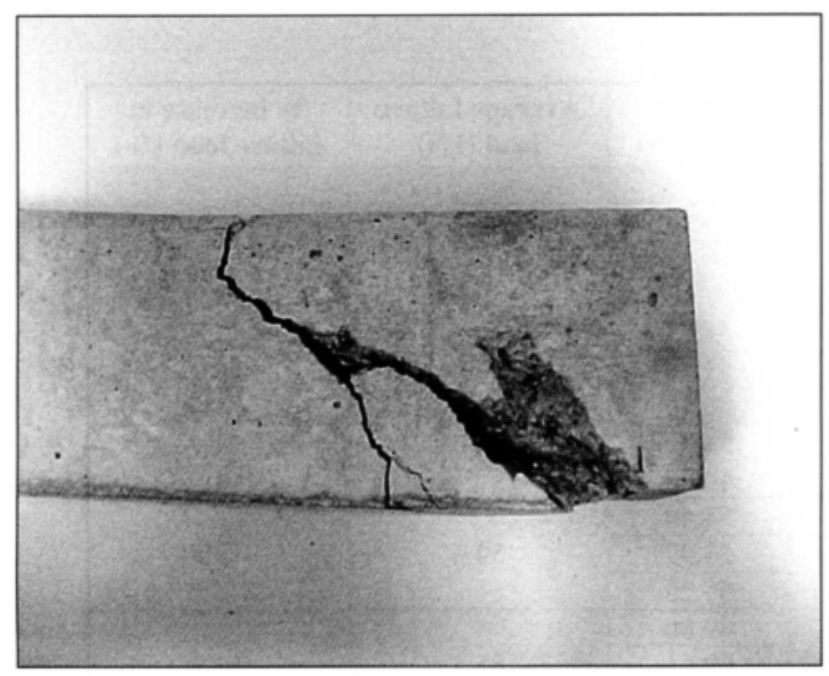

Fig 5. Control specimen at failure (close-up) beyond the shear capacity of control specimens, the strap debonding was first found at the vicinity of crack (Fig 6). Separation continued and spread to the far end of the strap. When the edge of strap was just detached, a sudden and large drop in load carrying capacity was recorded. After the test, one of the woven fabric straps was removed and a distinct shear crack was found (Fig 7). It was found in the concrete that the crack width was smaller than the one in the control case. It is clear that with the presence of this strap, the failure of beam is delayed, and thus gives rise to an enhanced load carrying capacity. It is also noted that a large portion of the concrete fragment was still bonded to the woven fabric strap, and the longitudinal steel rebar within the shear span could clearly be seen.

When specimens with larger straps were tested, their behaviour was rather similar to the two aforementioned conditions. Prior to reaching the shear capacity of the control specimen, shear cracks formed, but they could not be seen easily owing to the presence of the woven fabric strap. Once the shear capacity of the control speci-

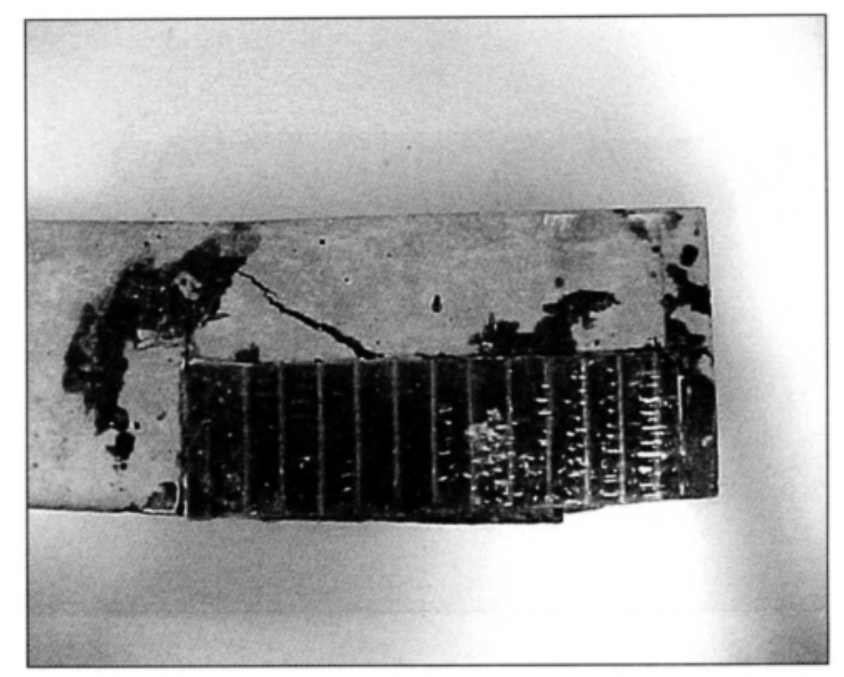

Fig 6. Strap debonding

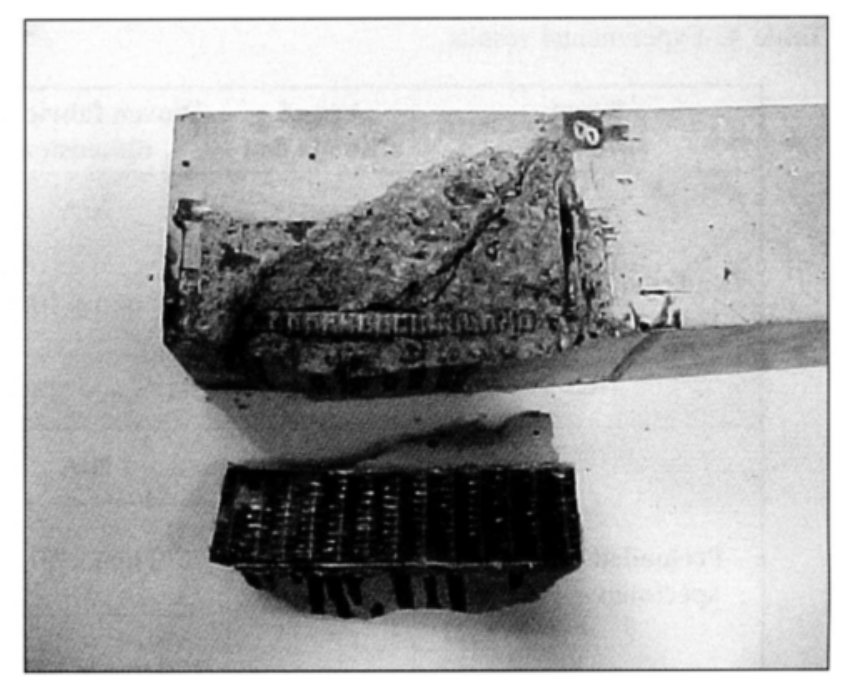

Fig 7. Shear crack below the strap 
men was exceeded, strap separations developed in the form of an inclined white stripe underneath the strap (Fig 8). It formed an angle larger than the crack angle formed in the control specimens and at the half-height of the repaired RC specimens. When the load was increased further, a wider white stripe was observed. A drop of load capacity was then recorded. No separation or partial detachment of straps was found. However, the shear crack at failure differed from the two previous cases. The crack appeared to develop just outside the constant moment region at an angle of $70 \mathrm{deg}$ (Fig 9). When the crack initiated from the top, it propagated to the level of longitudinal reinforcement and followed the rebar direction until another inclined crack was formed at the vicinity of the far end support. It is apparent that increasing the area of the strap further increases the load capacity of the shear span portion of the beam and changes the failure pattern. Unlike the half-height strengthening, no separation was found at the beam end. The observed failure mode can be explained by the fact

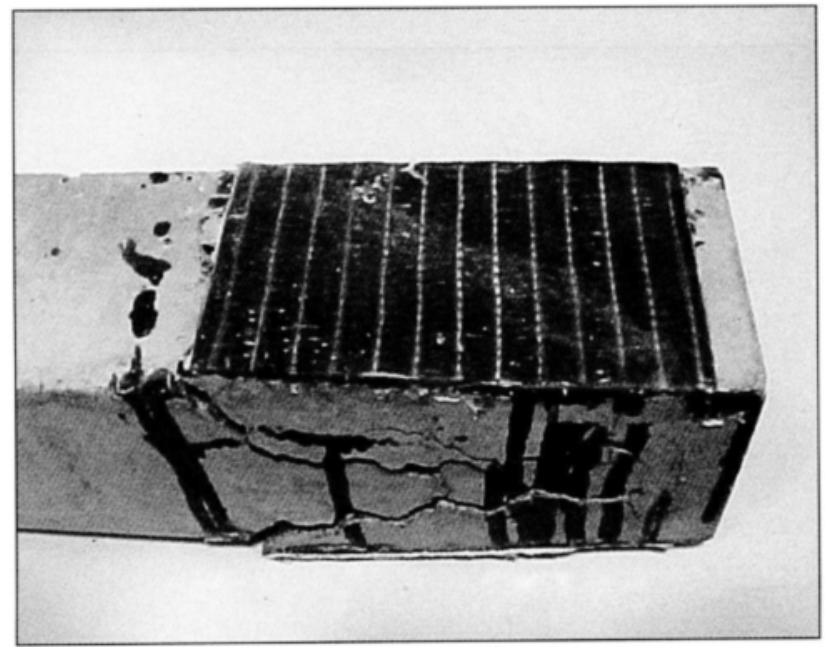

Fig 8. White stripes formed that bending and shear come into play, and the combined stresses act at the shear span region. At the supported end of the strap, bending moment is minimal and shear is dominant, whereas bending and shear are effective at the vicinity of the constant moment region. Concrete, with the presence of full-height straps, still cannot bear the combined stress and thus failure occurs. The failure pattern is of the bending-shear type.

\subsection{Failure load}

Two control, five strengthened beam specimens and three cylinders were tested to failure after 28 days. All other specimens, including six beams and three more cylinders, were preloaded at the same day, and then subjected to failure after 36 days. Average compressive cylinder strengths of $33,5 \mathrm{MPa}$ and $34,3 \mathrm{MPa}$ at 28 days and 36 days respectively were obtained The recorded flexural failure loads of the beam specimens are shown in Table 4.

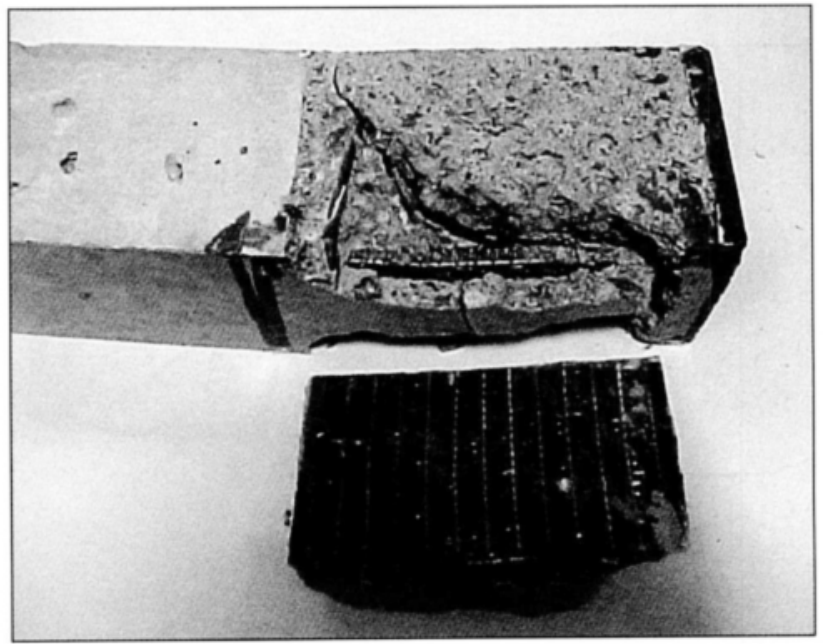

Fig 9. Shear crack below the large strap

Table 4. Experimental results

\begin{tabular}{|c|c|c|c|c|c|c|}
\hline \multicolumn{2}{|c|}{$\begin{array}{c}\text { Beam } \\
\text { specimen }\end{array}$} & $\begin{array}{c}\text { Age of } \\
\text { ultimate test }\end{array}$ & $\begin{array}{l}\text { Woven fabric strap } \\
\text { dimension }\end{array}$ & $\begin{array}{c}\text { Failure } \\
\text { load }(\mathbf{k N})\end{array}$ & $\begin{array}{l}\text { Average failure } \\
\text { load }(\mathbf{k N})\end{array}$ & $\begin{array}{c}\% \text { increase in } \\
\text { failure load }(\%)\end{array}$ \\
\hline \multirow{6}{*}{$\begin{array}{l}\text { Unpreloaded } \\
\text { specimen }\end{array}$} & NS1 & \multirow{6}{*}{28 days } & \multirow{2}{*}{ N/A } & 47,93 & \multirow{2}{*}{46,3} & \multirow{2}{*}{--} \\
\hline & NS2 & & & 44,74 & & \\
\hline & WH1 & & \multirow{3}{*}{$170 \mathrm{~mm} \times 50 \mathrm{~mm}$} & 50,34 & \multirow{3}{*}{52,6} & \multirow{3}{*}{13,5} \\
\hline & WH2 & & & 52,80 & & \\
\hline & WH3 & & & 54,69 & & \\
\hline & $\begin{array}{l}\text { WF1 } \\
\text { WF2 }\end{array}$ & & $170 \mathrm{~mm} \times 100 \mathrm{~mm}$ & 51,18 & 54,1 & 16,7 \\
\hline \multirow{8}{*}{$\begin{array}{l}\text { Preloaded } \\
\text { specimen }\end{array}$} & NS3 & \multirow{8}{*}{36 days } & \multirow{2}{*}{ N/A } & $\begin{array}{l}50,90 \\
51,85\end{array}$ & \multirow{2}{*}{48,3} & \multirow{2}{*}{$\cdots$} \\
\hline & NS4 & & & 44,80 & & \\
\hline & WHH1 & & \multirow{3}{*}{$170 \mathrm{~mm} \times 50 \mathrm{~mm}$} & 54,49 & \multirow{3}{*}{54,6} & \multirow{3}{*}{12,9} \\
\hline & WHH2 & & & 53,97 & & \\
\hline & WHH3 & & & 55,25 & & \\
\hline & WFH1 & & \multirow{3}{*}{$170 \mathrm{~mm} \times 100 \mathrm{~mm}$} & 49,86 & \multirow{3}{*}{55,5} & \multirow{3}{*}{14,9} \\
\hline & WFH2 & & & 60,61 & & \\
\hline & WFH3 & & & 56,10 & & \\
\hline
\end{tabular}


As seen in Table 4, improvement in failure load is found when external woven fabric straps are used. It is noteworthy that failure of the specimens occurred at maximum load for all specimens. The increase in load carrying capacity is not necessarily proportional to the area of the woven fabric strap. Instead, an increase of $13,5 \%$ and $16,7 \%$ was observed for half-height and full-height strengthening respectively. Increasing the area of woven fabric strap by $100 \%$ can only produce an additional $3,2 \%$ grow in the shear capacity.

When the preloading effect is taken into considerations, an increase in failure load is found when comparing the results of the control specimens NS1 \& NS2 with those of NS3 \& NS4. The slight increase may be due to the insignificant increase in concrete strength. However, when external woven fabric straps are applied to the preloaded specimens, the increase is more remarkable. Compared with the results derived from NS3 \& NS4, an increase of $12,9 \%$ and $14,9 \%$ is observed for half-height and full-height strengthening respectively. When preloading is applied, only an additional 2,0\% rise in load capacity can be obtained when the size of woven fabric strap is doubled.

It is also interesting to note that when preloading is applied, the ultimate load capacity is slightly increased. This demonstrates that external woven fabric straps are slightly more effective in strengthening preloaded RC beams than in the unloaded ones.

\section{Conclusions}

The current pilot experimental programme explores the use of woven fabric straps as external shear reinforcement. Half-height and full-height straps have been used to provide rehabilitation effect to both undamaged/ unpreloaded and damaged/preloaded beam specimens. From this study, it can be concluded that:

- The failure pattern of half-height strengthened specimens is similar to that of unstrengthened specimens. The only difference is that the crack width is reduced.

- Presence of woven fabric strap delays the failure by inhibiting the opening of the shear crack.

- Full-height strengthened specimens indicate a different failure pattern, a steeper crack is formed and no strap separation is observed.

- Externally bonded woven fabric straps can enhance the shear capacity of RC beam, but the increase in loading capacity is not necessarily proportional to the area of woven fabric strap.
- The increase in load capacity for half-height and full-height rehabilitation of preloaded RC beam specimens ranges from 12,9 to $16,7 \%$.

- External woven fabric straps are slightly more effective in strengthening preloaded RC beams than in the unloaded ones.

\section{Acknowledgements}

This study was conducted at the Heavy Structure Testing Laboratory, Department of Building and Construction, City University of Hong Kong, HKSAR and the authors would like to thank the technicians in the laboratory for providing assistance in specimen fabrication and testing. Thank is also extended to $\mathrm{Mr}$ Anthony Poon of MTS (Hong Kong) for giving advice and support on equipment preparation and operation. Besides, the work described in this paper was fully supported by a grant from the City University of Hong Kong (Project No: 9030935).

\section{References}

1. Neelamegam, M.; Dattatreya, J. K.; Parameswaran, V. S and Gopalakrishnan, S. Performance of RC beams with externally bonded steel plates. In: Proceedings of international symposium on innovative world of concrete' 98 , Vol II, Calcutta, India, 1998, p. 14.31-14.38.

2. Mohamed Ali, M. S.; Oehlers, D. J. and Bradford, M. A. Shear peeling of steel plates adhesively bonded to the sides of reinforced concrete beams. In: Proceedings ICE, Structures \& buildings, Vol 140, Aug, 2000, p. 249-259.

3. Varastehpour, H. and Hamelin, P. Strengthening of concrete beams using fiber-reinforced plastics. Materials and structures, Vol 30, April, 1997, p. 160-166.

4. Ross, C. A.; Ferome, D. M.; Tedesco, J. W. and Hughes, M. L. Strengthening of reinforced concrete beams with externally bonded composite laminates. $A C I$ structural journal, Vol 96, No 2, 1999, p. 212-220.

5. Sherwood, E. G. and Soudki, K. A. Rehabilitation of corrosion damaged concrete beams with CFRP laminates - a pilot study. Composites part B: Engineering, Vol 31, 2000, p. $453-459$.

6. Ramana, V. P. V.; Kant, T.; Morton, S. E.; Dutta, P. K.; Mukherjee, A. and Desai, Y. M. Behavior of CFRPC strengthened reinforced concrete beams with carrying degrees of strengthening. Composites part B: Engineering, Vol 31, 2000, p. 461-470.

7. Teng, J. G.; Chen, J. F.; Smith, S. T. and Lam, L. FRP Strengthened RC structures. John Wiley \& Sons, Ltd., England, 2001. 